\title{
Homology Modelling, In Silico Prediction And Characterization Of Cytochrome c oxidase In Cyprinus carpio And Tubifex tubifex And Molecular Docking Studies Between The Modelled Protein And Three Commonly Used Surfactants Sodium Dodecyl Sulphate, Cetylpyridinium Chloride And Sodium Laureth Sulphate
}

\author{
Ritwick Bhattacharya $^{1}$, Ismail Daoud ${ }^{2,3}$, Arnab Chatterjee ${ }^{1}$, Soumendranath Chatterjee ${ }^{4}$, \\ Nimai Chandra Saha ${ }^{1 *}$
}

${ }^{1}$ Fishery and Ecotoxicology Research Laboratory (Vice-Chancellor's Research Group), Department of Zoology, The University of Burdwan, Burdwan 713104, West Bengal, India.

${ }^{2}$ Laboratory of Natural and Bioactive Substances, University of Abou-Bakr Belkaid, Tlemcen, Algeria.

${ }^{3}$ Department of Matter Sciences, University of Mohamed Khider Biskra, BP 145 RP, 07000 Biskra, Algeria.

${ }^{4}$ Parasitology \& Microbiology Research Laboratory, Department of Zoology, The University of Burdwan, Burdwan, West Bengal, India.

*Corresponding author: research.ncsaha@gmail.com, ncsaha@zoo.buruniv.ac.in 


\begin{abstract}
The purpose of this work is to evaluate the homology modeling, in silico prediction, and characterisation of Cytochrome c oxidase from Cyprinus carpio and Tubifex tubifex, as well as molecular docking experiments between the modelled protein and three frequently used surfactants. Using the template crystal structure of bovine heart Cytochrome c oxidase, homology modeling of Cytochrome c oxidase (Subunit 2) of Cyprinus carpio (Accession \# P24985) and Cytochrome c oxidase (Subunit 1) of Tubifex tubifex (Accession \# Q7YAA6) was conducted. The model structure was improved further with $3^{\mathrm{D}}$ refine, and the final $3 \mathrm{D}$ structure was verified with PROCHEK and ERRATA. The physiochemical, as well as the stereochemical parameters of the modelled protein, were evaluated using various tools like ExPASy's ProtParam, Hydropathy Analysis and EMBOSS pepwheel. The projected model was then docked with toxic ligands, Sodium dodecyl sulfate (SDS), Cetylpyridinium chloride (CPC), and Sodium laureth sulfate (SLES), whose 3D structures were obtained from the Uniprot database. CPC interacted best with Cytochrome c oxidase subunit 2 of Cyprinus carpio and Cytochrome c oxidase subunit 1 of Tubifex tubifex, according to our findings. Furthermore, in the case of all surfactants, hydrophobic interactions with the active site amino acid residues of the modelled protein were observed to be more common than hydrogen bonds and salt bridges. Molecular simulation studies exhibited that the surfactants alter the structural flexibility of the predicted proteins. Hence it may be inferred that the surfactants might alter the structure and dynamics of Cytochrome c oxidase of both worm and fish.
\end{abstract}

Keywords: Homology modelling, Cytochrome c oxidase, Molecular docking, Molecular simulation 


\section{Introduction}

Surfactants basically used in personal care products exert detrimental effects on different target as well as non-target organisms which further may also affect humans by biomagnification (Ebele et al. 2017). They are perilous to macromolecules and alter their efficient functioning in the biological system by annexing with them (Ivanković and Hrenović 2010). Several studies have documented the toxic effects of surfactants in aquatic organisms (Lechuga et al. 2016, Freitas et al. 2019, Freitas, Silvestro, Coppola, et al. 2020, Freitas, Silvestro, Pagano, et al. 2020, Hering et al. 2020, Mustapha and Bawa-Allah 2020). The surfactants are entirely categorized into anionic, nonionic, cationic and zwitterionic surfactants (Jackson et al. 2016). The most bountiful class of surfactants that are prodigiously utilized in household detergents and industrial cleaning products are anionic surfactants (Ivanković and Hrenović 2010). The most commercially used anionic surfactants especially utilized for household products, cosmetics, and laundry purposes are soidum dodecyl sulphate (SDS) and sodium laureth sulphate (SLES) (Bondi et al. 2015, Barra Caracciolo et al. 2017). It has been accounted for that the survivability of fishes and microorganisms are antagonistically influenced by anionic surfactants (Chaturvedi and Kumar 2010). On the other hand cationic surfactants are molecules with a long, hydrophobic chain connected to the positive nitrogen atom (Puchta 1984). These are more poisonous contrasted with anionic surfactants (Jardak et al. 2016). This group of surfactants is commonly utilized in sundry sectors such as textiles, emulsifiers, wetting agents, disinfectants, and cosmetics (Puchta 1984, Jardak et al. 2016). Predicated on the previous studies, it is observed that quaternary ammonium compounds are the most abundant and widely utilized class of cationic surfactant (Zhang et al. 2015). Cetylpyridinium chloride (CPC) is indeed a quaternary ammonium cationic component that is deliberately used in mouthwashes for the elimination of dental plaques and periodontitis. Besides, it also eliminates reactive dyes, phenols, and different organic solutes from waste products or treated effluents (Costa et al. 2013).

Cytochrome c oxidase $(\mathrm{CcO})$ is the terminal oxidase of the mitochondrial electron transport chain that catalyzes the reduction of molecular oxygen to water (Wikström et al. 2018). Any toxicant induced dysfunction or modifications in Cytochrome c oxidase, facilitates oxidative stress by inducing mitochondrial apoptosis (Srinivasan and Avadhani 2012). The protein structure prediction methods include developing a three-dimensional protein structure from its monomer (amine acid). Relatively few protein structures are known in the protein database 
and the number of sequences has risen considerably faster than the number of protein structure available owing to advancements in DNA sequencing. Homology protein modeling is a systematic approach in the study of protein structure. It gives an insight into the underlying characteristics of proteins and is used to predict the three-dimensional structure (3D). Moreover molecular docking are essential method to identify the effect of hazardous ligands or chemicals by recognizing patterns of inter-molecular interactions with the desired proteins (Dhandare et al. 2020).

Several pieces of research were conducted regarding the induction of stress in aquatic organisms upon addition of surfactant (Bhattacharya et al. 2019a, 2019b, 2021). Moreover, several researches were also conducted regarding the dysfunction of Cytochrome c oxidase upon addition of several toxicant (Leavesley et al. 2008). However, evidence regarding the In silico assessment of the effects of surfactants (SDS, SLES, and CPC) to Cytochrome c oxidase on aquatic organism is meager.

We predicted and analyzed Cytochrome c oxidase from both Cyprinus carpio and Tubifex tubifex as potential receptor proteins in this work. Based on qualitative and quantitative characteristics, the predicted protein was deemed to be satisfactory and was docked with three commonly used surfactants SDS, CPC, and SLES. Moreover the study was elaborated to note the pattern of interactions between SDS, CPC, SLES and the protein Cytochrome c oxidase, which may serve as a potential implement to assess the effects of the surfactants on stress related proteins in aquatic organisms.

\section{Materials and methods}

\section{Sequence Retrieval, Modeling and Prediction of target protein}

The FASTA sequence of Cytochrome c oxidase (Subunit 2) of Cyprinus carpio (Accession \# P24985) and Cytochrome c oxidase (Subunit 1) of Tubifex tubifex (Accession \# Q7YAA6) were retrieved from Uniprot (https://www.uniprot.org/). For homology modeling the 3d structure of the target protein is constructed using SWISS MODEL. It is a fully automated protein structure homology-modelling server, accessible via the Expasy server (Bienert et al. 2017, Waterhouse et al. 2018). The PDB templates used for the construction of target protein was 3abm.1.B (Cytochrome c oxidase subunit 2 of bovine heart, resolution $1.95 \AA$ ) having sequence identity: $71.81 \%$ with the modelled protein Cytochrome c oxidase (Subunit 2) of Cyprinus carpio and 3abm.1.A (Cytochrome c oxidase subunit 2 of bovine heart, 
resolution $1.95 \AA$ ) having sequence identity $76.23 \%$ with the modelled protein Cytochrome c oxidase (Subunit 1) of Tubifex tubifex.

\section{Refinement, Evaluation, and Validation of Protein Model}

The predicted protein structures are refined using 3Drefine. It is an online interactive server enabling computationally efficient protein structure refinement with web-based statistics and graphical analysis capabilities. For effective protein structure refinement, the refinement technique employs repeated optimization of the hydrogen bonding network along with atomic-level energy reduction on the optimized model utilizing a combined physics and knowledge-based force fields (Bhattacharya and Cheng 2013). The structures are further evaluated and validated using PROCHECK by constructing Ramachandran plot (Laskowski et al. 1993) and ERRAT score (Colovos and Yeates 1993). The Ramachandran plot visualizes the dihedral angles phi and psi of amino acid residues in protein structure and delineates the potential allowed and disallowed configurations of protein structure, whereas the ERRAT interface performs on the statistics of non-bonded atomic interactions and atom allocation (Colovos and Yeates 1993, Laskowski et al. 1993).

\section{Physicochemical Parameter Analysis}

ExPASy's ProtParam method is used to determine different calculated physiochemical parameters of predicted protein such as number of amino acids, molecular weight, theoretical pI, aliphatic index (AI), and grand average of hydropathicity (GRAVY) (Gasteiger et al. 1999). Hydropathy Analysis is utilized to determine hydropathy and amphipathicity of the predicted protein, and EMBOSS Pepwheel is used to emphasize amphipathicity and other characteristics of residues around a helix by displaying them in a wheel diagram, which is available in The Transporter Classification Database (Saier et al. 2016). GOR IV server is used for prediction of secondary structures of the modelled proteins.

\section{Retreival of Toxic Ligands}

$3 \mathrm{~d}$ conformers of three commonly used surfactants, sodium dodecyl sulphate (SDS), cetylpyridinium chloride (CPC) and sodium laureth sulphate (SLES) were obtained from the PubChem Compound Database (https://pubchem.ncbi.nlm.nih.gov/) in structure data file (sdf) and canonical Simplified Molecular Input Line Entry Specification (SMILES) format.

\section{Protein-Ligand Docking Study}


Prior to docking docking, the predicted protein file was loaded into Biovia Discovery studio for preparation steps. The steps included the addition of polar hydrogen, Kollman charges as well as removal of heteroatoms. Removal of water is not necessary as the presence of water is essential to ensure a relay between the compound and the active site and thus create networks of hydrogen bonds (Klebe 2006). On the other hand water molecules in the cavities of proteins can sometimes be a fundamental element as some algorithms are able to simulate the presence of water molecules in the cavities of proteins (Marechal 2007). The binding affinity of 3 surfactants with target protein is predicted using CB-Dock (Cavity-detection guided Blind Docking) which is designed to perform blind docking at predicted sites, instead of the entire surface of a protein. It implements Autodoc Vina (1.12) for performing docking analysis (Liu et al. 2020). The docking pose of the ligand protein complex was selected based on the lowest vina score and RMSD value of less than 2 Angstrom (Liu et al. 2020). Finally, the bond type and interaction between active site residues of protein and ligand was obtained by using Protein-Ligand Interaction Profiler (PLIP) which aids in easy and fast identification of intermolecular interactions between biological macromolecules and their ligands (Salentin et al. 2015, Adasme et al. 2021).

\section{Molecular Dynamics Simulation studies}

The simulations of molecular dynamics (MD) were conducted with the CABS-flex 2.0 server to evaluate the structural flexibilities of the proteins alone and compare it to the protein ligand docking complex (Kurcinski et al. 2019). Based on the MD trajectory and default variables the root-mean-square fluctuations (RMSF) were determined. In recent years, several researchers relied on this server for protein ligand simulation studies (Arora et al. 2020, Vardhan and Sahoo 2020, Shah et al. 2021).

\section{Results and Discussions}

\section{Structure prediction and model evaluation of target protein}

Fig. 1 shows modelled predicted structure of the target protein, as determined by SWISS MODEL (Waterhouse et al. 2018). Ramachandran plot shows the percentage of residues in favourable regions, additionally allowed regions, generously allowed regions, and disallowed regions. The Ramachandran plot obtained through PROCHEK server (Laskowski et al. 1993) revealed that our predicted protein model of Cyprinus carpio and Tubifex tubifex had $90.1 \%$ and $94.2 \%$ residues respectively, lying in the most allowed region which qualifies it as a good 
bioRxiv preprint doi: https://doi.org/10.1101/2021.07.09.451643; this version posted July 10, 2021. The copyright holder for this preprin (which was not certified by peer review) is the author/funder, who has granted bioRxiv a license to display the preprint in perpetuity. It is made available under aCC-BY-ND 4.0 International license.

model as according to PROCHEK (a good quality model is expected to have $>90 \%$ residues in the most favourable region). Moreover, no residues were present in the disallowed region (Fig 2). The overall quality factor and compatibility of the model with amino acid residues were evaluated using ERRAT (Colovos and Yeates 1993) which was calculated as 90.2778 and 94.9622 respectively. In general, the modelled protein is considered good if the quality factor is $>50$ (Khusro et al. 2020).
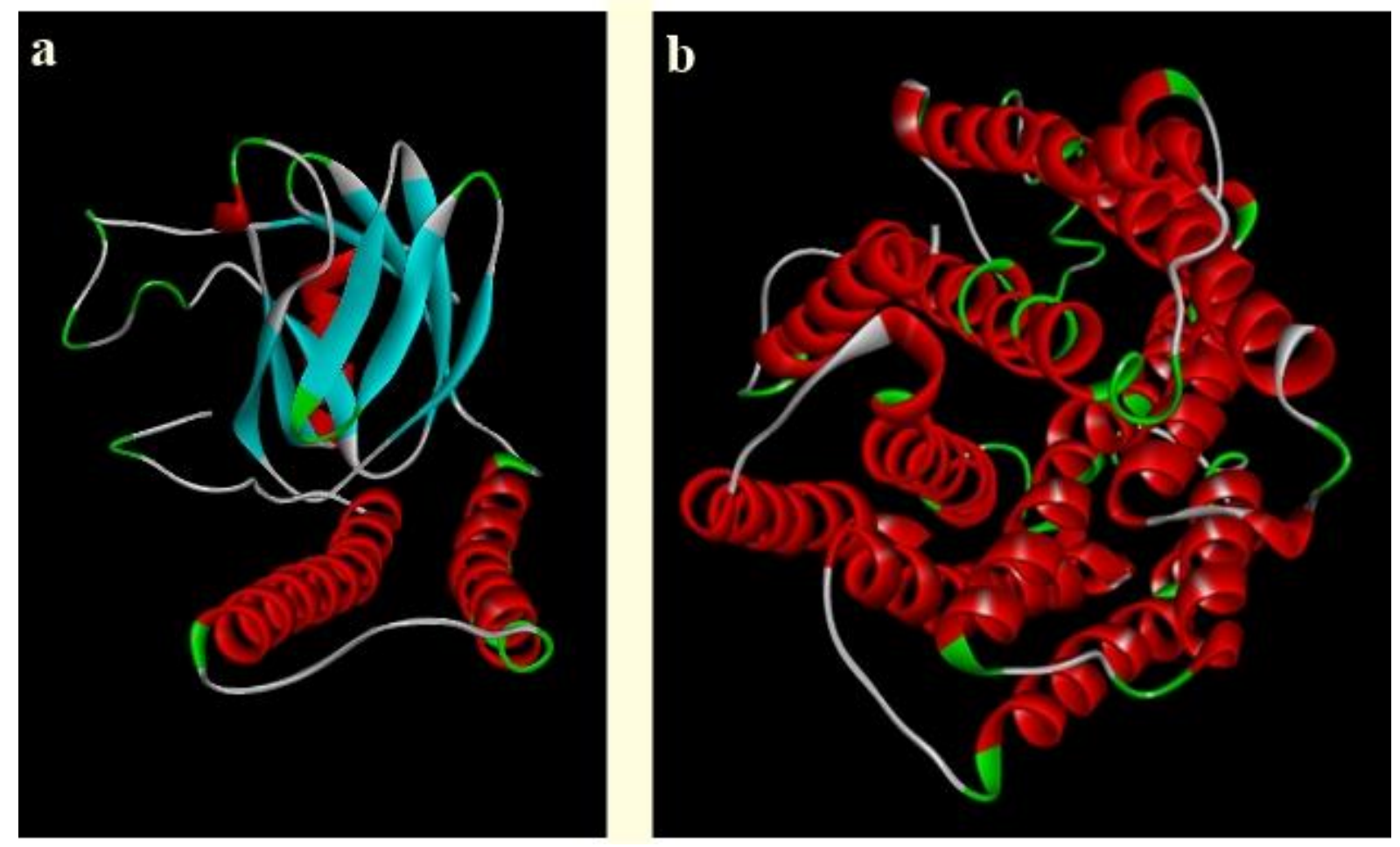

Fig 1: Predicted structure of : (a): Cytochrome c oxidase subunit 2 of Cyprinus carpioand (b): Cytochrome c oxidase subunit 1 (Tubifex tubifex). 


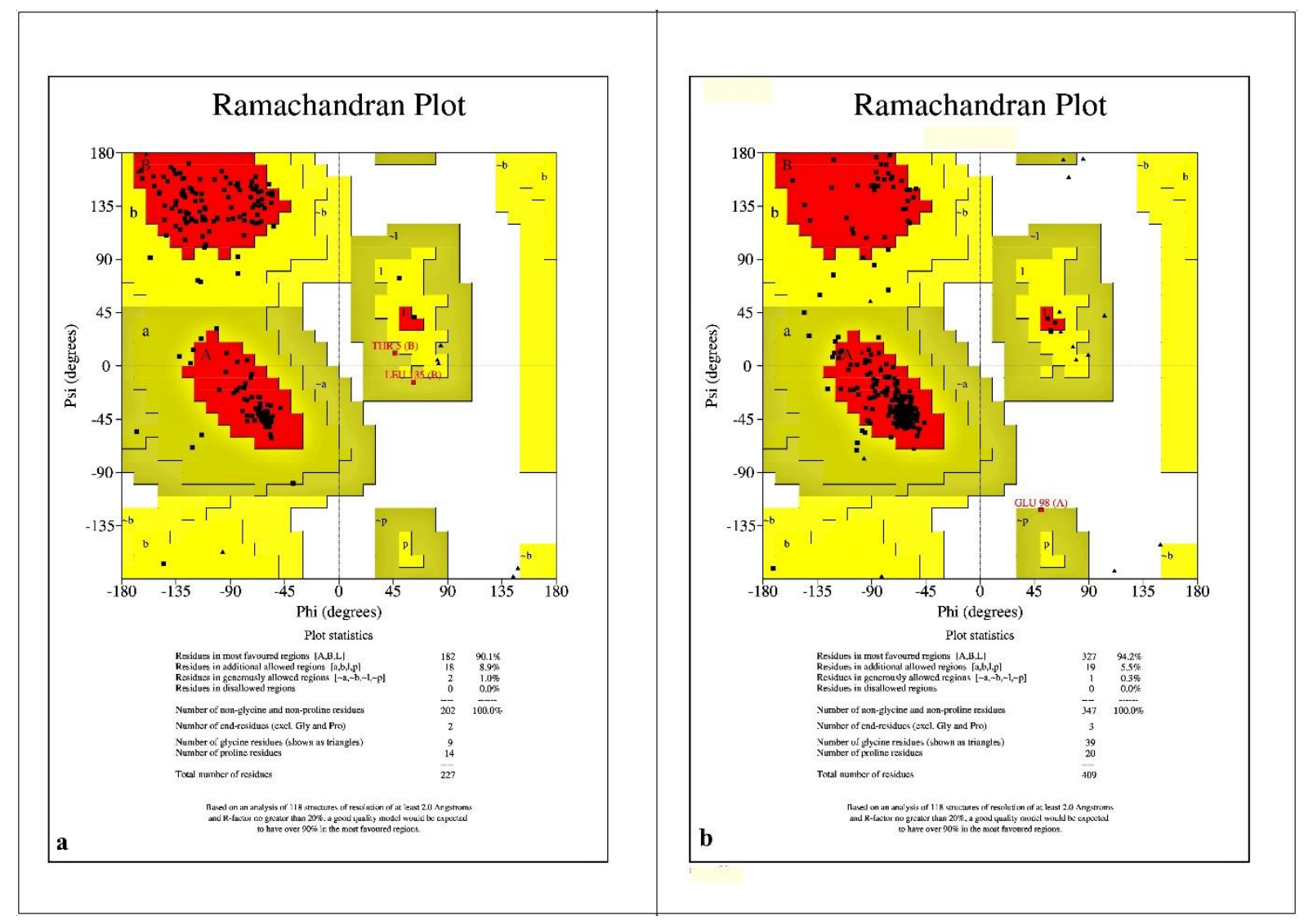

Fig 2: Ramachandran plot of: (a): Cytochrome c oxidase subunit 2 of Cyprinus carpio and (b): Cytochrome c oxidase subunit 1 of Tubifex tubifex.

\section{Physiochemical properties of the modelled proteins}

Physiochemical parameters are the preliminary attributes of proteins that exemplify their distinctiveness. (Khusro et al. 2020) Results for physiochemical parameters of predicted protein model of Cyprinus carpio and Tubifex tubifex are shown in Table 1. The $\mathrm{pH}$ where the surface of a protein is charged but the net charge of the protein is zero is known as the isoelectric point $(\mathrm{pI})$. If the theoretical $\mathrm{pI}$ value is more than 7 , the macromolecule has an alkaline nature whereas the predicted $\mathrm{pI}<7$ shows the acidity of the molecule (Shaw et al. 2001). In this context, theoretical pI of Cytochrome c oxidase subunit 2 of Cyprinus carpio and Cytochrome c oxidase subunit 1 (Tubifex tubifex) were determined acidic and alkaline in nature respectively. The aliphatic index (AI) is a measure used to assess protein stability. AI can be determined by the relative volume occupied by the aliphatic side chains of amino acids in a protein. A high aliphatic index value of more than 50 indicates that the protein is temperature stable. In general, the aliphatic index is closely attributed to the protein or peptide's thermostability (Kaur et al. 2020). In this study, the modelled protein Cytochrome c oxidase subunit 2 of Cyprinus carpio and Cytochrome c oxidase subunit 1 of Tubifex tubifex 
exhibited the aliphatic index value of 110.61 and 113.31, which indicates that the predicted proteins are highly thermostable. The hydrophobicity value of a peptide is expressed by the grand average of hydropathicity index (GRAVY), which calculates the total of the hydropathy values of all the amino acids divided by the sequence length. Positive GRAVY values imply hydrophobic properties, whereas negative ones suggest hydrophilic properties (Chang and Yang 2013). Based on the GRAVY values, Cytochrome c oxidase subunit 2 of Cyprinus carpio and Cytochrome c oxidase subunit 1 of Tubifex tubifex are hydrophobic in nature.

Table 1: Some Physiochemical parameters of modelled proteins

\begin{tabular}{|c|c|c|c|c|}
\hline \multirow{2}{*}{ Modelled proteins } & \multicolumn{3}{|c|}{ Physiochemical parameters } \\
\cline { 2 - 5 } & $\begin{array}{c}\text { Number of } \\
\text { amino acids }\end{array}$ & $\begin{array}{c}\text { Theoretical } \\
\text { pI }\end{array}$ & $\begin{array}{c}\text { Aliphatic } \\
\text { index }\end{array}$ & GRAVY \\
\hline $\begin{array}{c}\text { Cytochrome c oxidase subunit 2 } \\
\text { (Cyprinus carpio) }\end{array}$ & 230 & 4.79 & 110.61 & 0.327 \\
\hline $\begin{array}{c}\text { Cytochrome c oxidase subunit 1 } \\
\text { (Tubifex tubifex) }\end{array}$ & 408 & 7.44 & 113.31 & 0.825 \\
\hline
\end{tabular}

\section{Primary structure analysis of modelled proteins}

The primary structure of peptides reflects the amino acid makeup (Breda et al. 2007). The amino acid composition of the modelled proteins Cytochrome c oxidase subunit 2 of Cyprinus carpio and Cytochrome c oxidase subunit 1 of Tubifex tubifex is shown in Fig. 3. In this scenario, Leucine is the most abundant amino acid in the modelled proteins of both Cytochrome c oxidase subunit 2 of Cyprinus carpio (with $\approx 12 \%$ ) and Cytochrome c oxidase subunit 1 of Tubifex tubifex (with $\approx 14 \%$ ). Furthermore, the proportion of Glycine in Cytochrome c oxidase subunit 1 of Tubifex tubifex (with $\approx 10 \%$ ) is greater than Cytochrome c oxidase subunit 2 of Cyprinus carpio (with $\approx 4 \%$ ) (Khusro et al. 2020). 


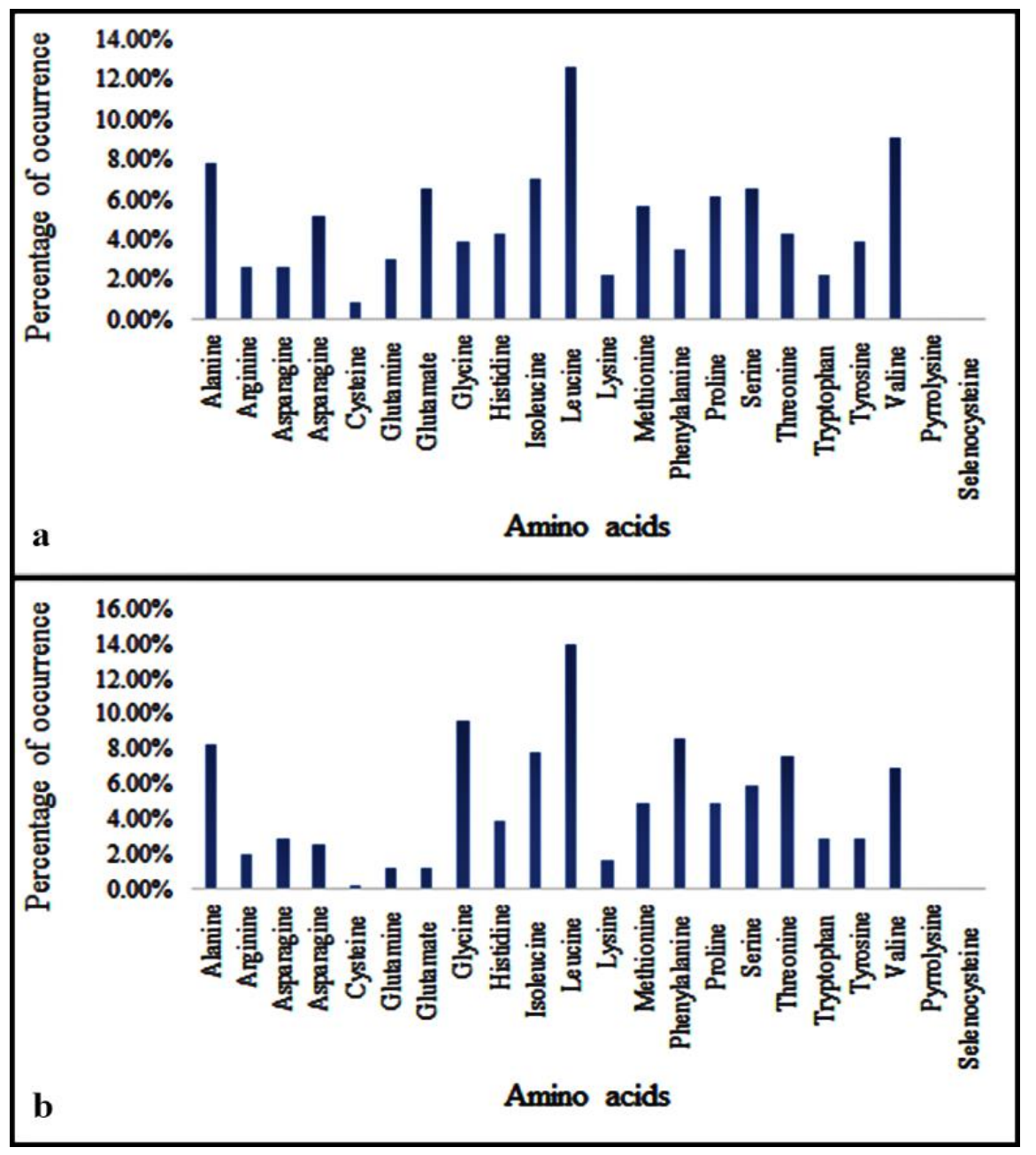

Fig 3: Amino acid composition (\%) of: (a): Cytochrome c oxidase subunit 2 of Cyprinus carpio and (b): Cytochrome c oxidase subunit 1 of Tubifex tubifex.

\section{Secondary structure analysis of peptide}

The secondary structure of both the modelled proteins of Cytochrome c oxidase subunit 2 of Cyprinus carpio and Cytochrome c oxidase subunit 1 of Tubifex tubifex consists principally of an alpha helix, an extended strand segment, $\beta$-turn, and a random coil (Fig 4). However, the sequence of dominance of the secondary structure in Cytochrome c oxidase subunit 2 of Cyprinus carpio is Random coil > Alpha helix > Extended strand > $\beta$-turn, but in Cytochrome c oxidase subunit 1 of Tubifex tubifex the order of dominance is Alpha helix $>$ Random coil > Extended strand > $\beta$-turn. Furthermore, the proportion of $\beta$-turn is greater in Cytochrome c oxidase subunit 1 of Tubifex tubifex than in Cytochrome c oxidase subunit 2 of Cyprinus carpio, indicating that Cytochrome c oxidase subunit 1 of Tubifex tubifex has a slightly poorer structural stability than Cytochrome c oxidase subunit 2 of Cyprinus carpio as 
presence of $\beta$-turn in protein secondary structure negative impacts the stabiluty of the protein (Khusro et al. 2020)

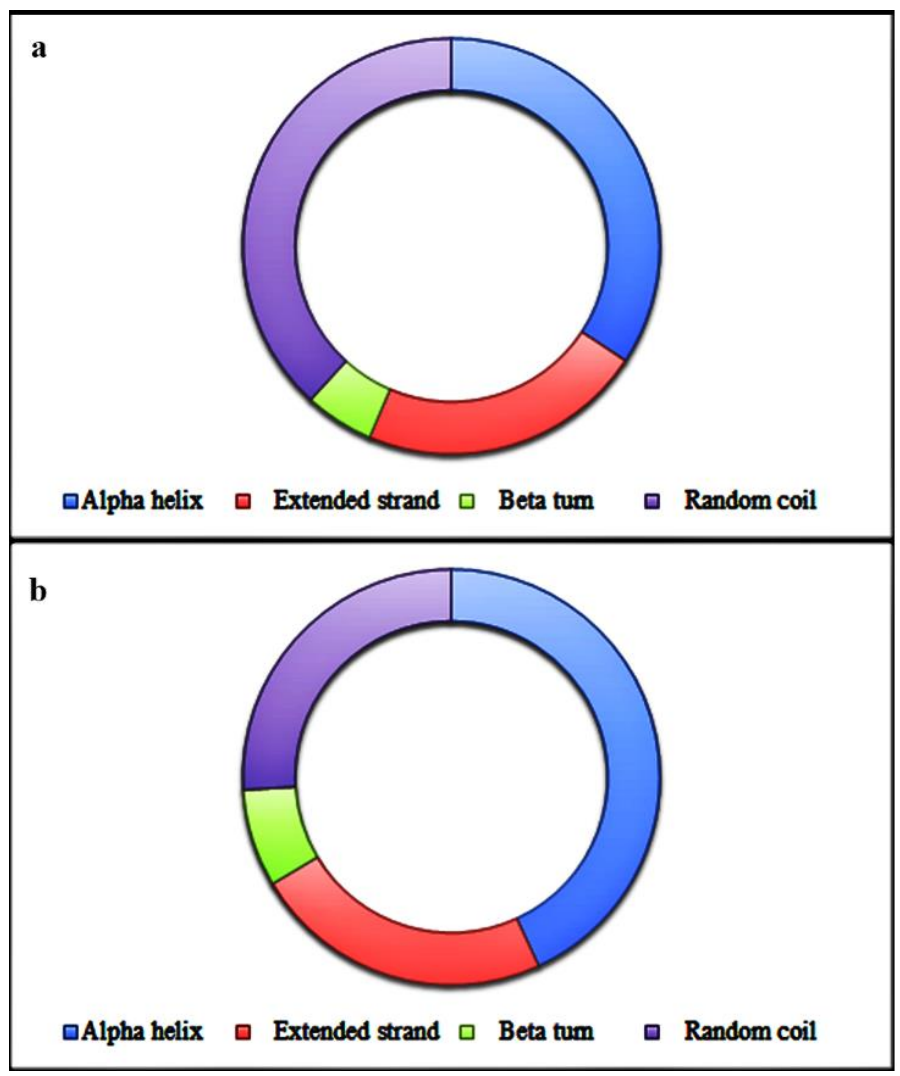

Fig 4: Prevalance of Alpha helix, extended strand region, $\beta$-turn, and random coil in (a): Cytochrome c oxidase subunit 2 of Cyprinus carpioand (b): Cytochrome c oxidase subunit 1 of Tubifex tubifex

\section{Functional analysis of modelled protein}

Hydropathicity and membrane-spanning properties of Cytochrome c oxidase subunit 2 of Cyprinus carpio and Cytochrome c oxidase subunit 1 of Tubifex tubifex are illustrated in Fig 5, which showed that Cytochrome c oxidase subunit 2 of Cyprinus carpio has two transmembrane regions while Cytochrome c oxidase subunit 1 of Tubifex tubifex has ten. This suggests that the frequency of transmembrane segments is greater in Cytochrome c oxidase subunit 1 of Tubifex tubifex. Furthermore, the helical wheel diagram depicts the protein sequence in a helical format. It may be used to highlight amphipathicity and other characteristics of residues surrounding a helix (Schiffer and Edmundson 1967). The helical wheel prediction of modelled proteins Cytochrome c oxidase subunit 2 of Cyprinus carpio and Cytochrome c oxidase subunit 1 of Tubifex tubifex is shown in Fig. 6, revealing the 
bioRxiv preprint doi: https://doi.org/101101/2021.07.09.451643. this version posted July 10,2021 . The copyright holder for this preprin (which was not certified by peer review) is the author/funder, who has granted bioRxiv a license to display the preprint in perpetuity. It is made available under aCC-BY-ND 4.0 International license.

allocation of hydrophilic, alipathic, and positively charged residues of Cytochrome c oxidase subunit 2 of Cyprinus carpio and Cytochrome c oxidase subunit 1 of Tubifex tubifex.

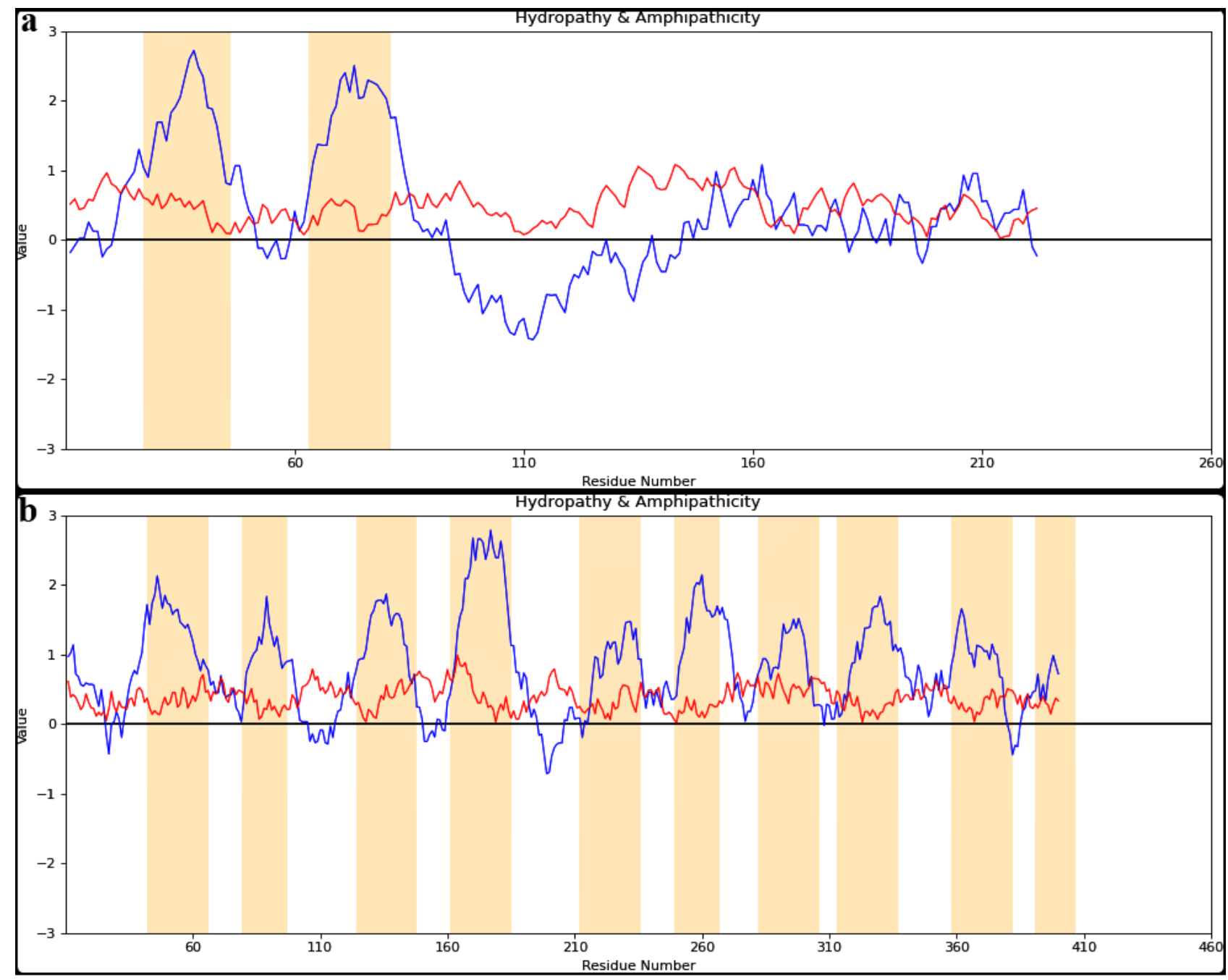

Fig 5: Hydropathicity, amphipathicity and transmembrane segments of (a): Cytochrome c oxidase subunit 2 of Cyprinus carpio and (b): Cytochrome c oxidase subunit 1 of Tubifex tubifex. Blue lines denote Hydropathy, Red lines denote Amphipathicity and Orange bars mark transmembrane segments. 


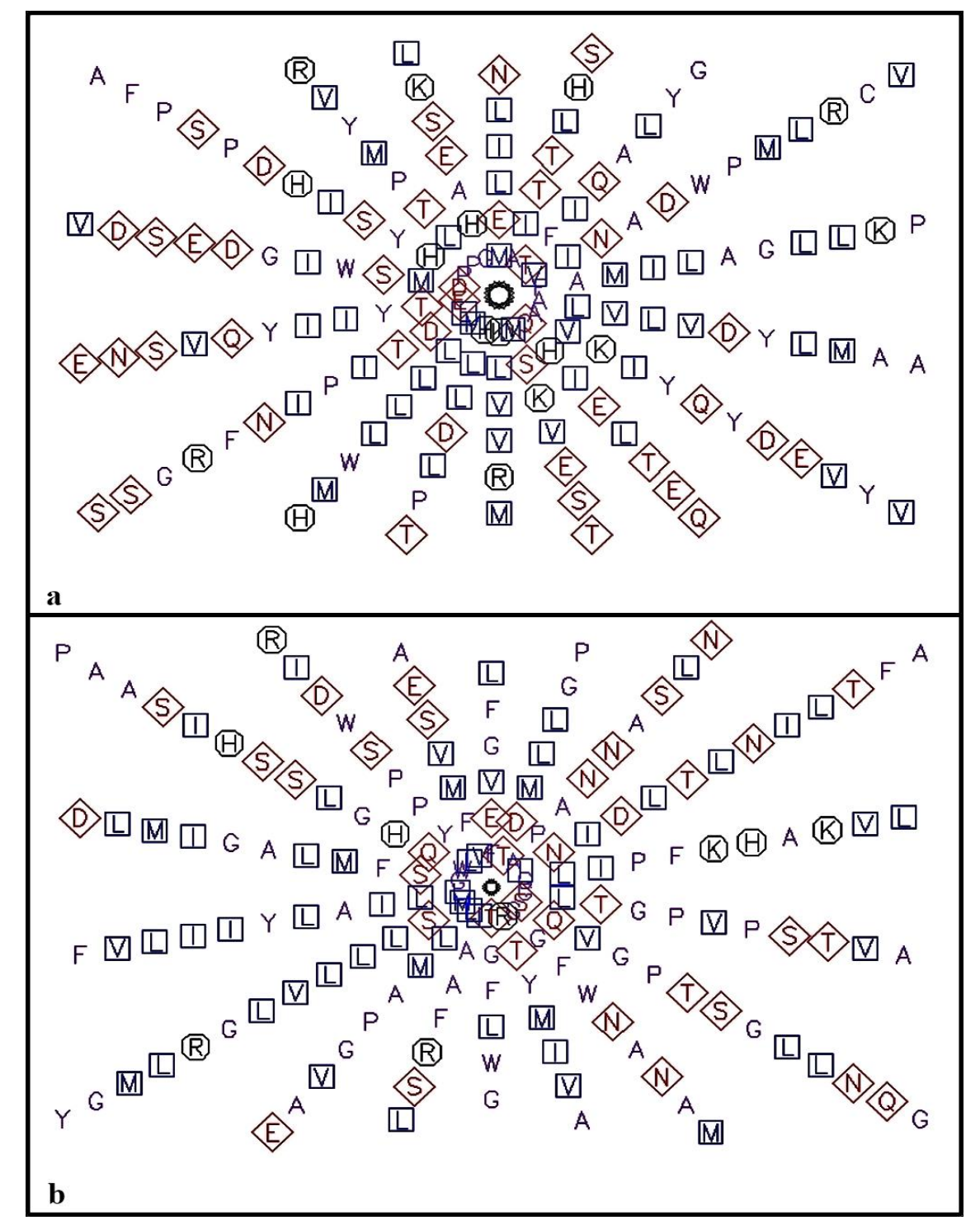

Fig 6: The helical wheel prediction of (a): Cytochrome c oxidase subunit 2 of Cyprinus carpioand (b): Cytochrome c oxidase subunit 1 of Tubifex tubifex. Aliphatic residues are marked with squares, hydrophilic residues are marked with diamonds, and positively charged residues with octagons.

\section{Protein-Ligand Docking}

The 3D structure of the surfactant protein interaction in both fish and worm are provided in Fig. 7. The docking pose of the ligand protein complex was selected based on the lowest vina score and Root mean square deviation (RMSD) value of less than $2 \AA$ (Liu et al. 2020) The root-mean square deviation (RMSD) was used to determine how different the docking orientation achieved is from the equivalent co-crystallized posture of the identical ligand molecule.. Basically three different RMSD classifications are used for docking solutions: (a) 
good solution when RMSD $\leq 2.0 \AA$ (b) acceptable solutions when RMSD is between 2.0 and $3.0 \AA$, and (c) bad solutions when RMSD $\geq 3.0 \AA$ (Ramírez and Caballero 2018).

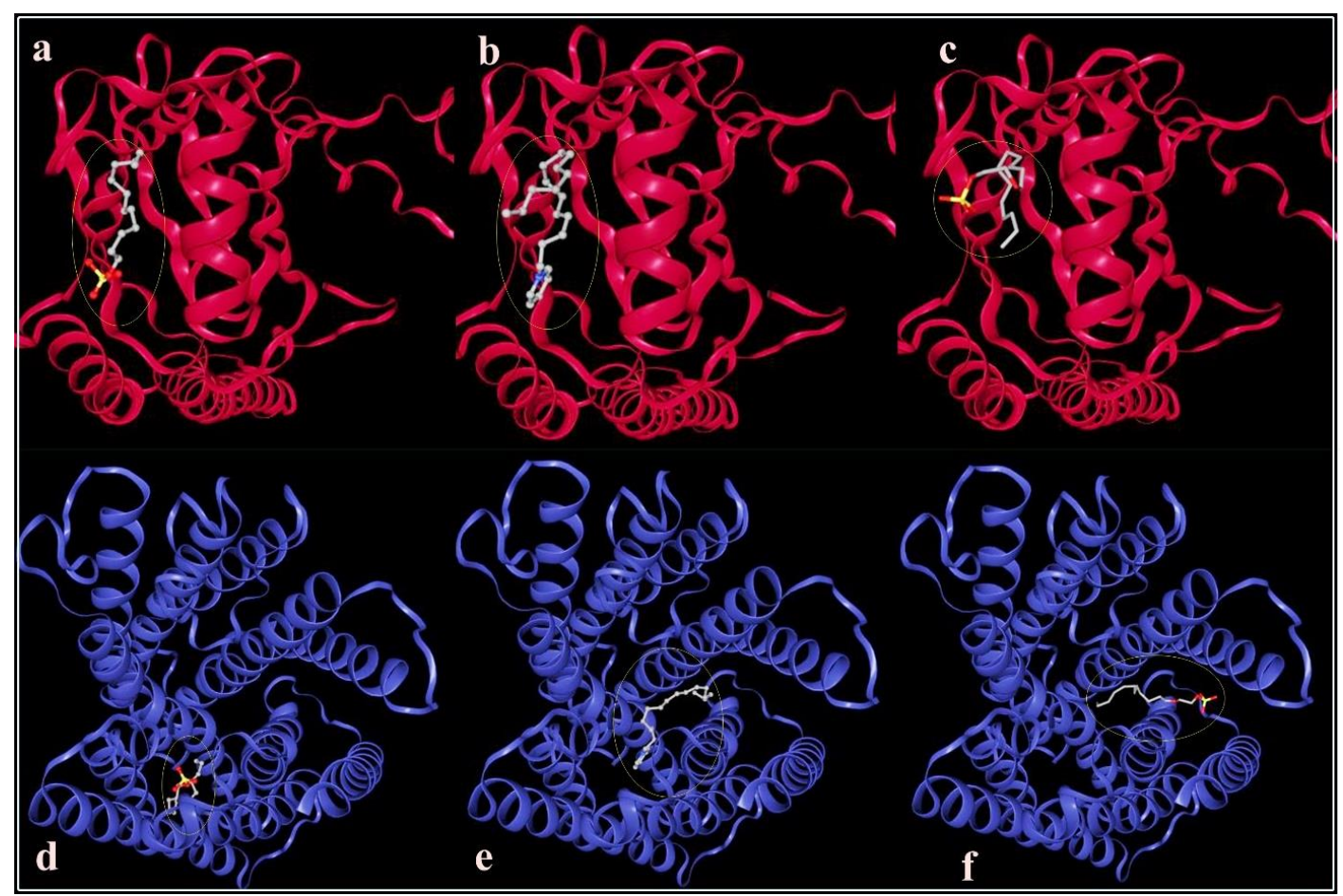

Fig 7: 3D structure of docking between (a): Cytochrome c oxidase subunit 2 of Cyprinus carpio and SDS, (b):Cytochrome c oxidase subunit 2 of Cyprinus carpio and CPC, (c): Cytochrome c oxidase subunit 2 of Cyprinus carpio and SLES, (d): Cytochrome c oxidase subunit 1 of Tubifex tubifex and SDS (e): Cytochrome c oxidase subunit 1 of Tubifex tubifex and CPC, (f): Cytochrome c oxidase subunit 1 of Tubifex tubifex and SLES. The ball and stick structure represent the ligand.

Vina score is a quantitative scoring function that determines the affinity, or efficiency, of protein-ligand interactions (Liu and Wang 2015). Low Vina scores indicate high binding affinity between protein and ligand (Wójcikowski et al. 2017). The vina scores of surfactant protein complex is displayed in Table 2. Surfactant protein interaction profile analysis are mainly focused on hydrogen bonds and hydrophobic interaction and to some extent salt bridge. Hydrogen bonds greatly influence the value of binding affinity. The strength of hydrogen bonds can be subdivided dependent on the distance between the interactions. Hydrogen bonds with a distance of 2.2-2.5 $\AA$ are considered strong, 2.5-3.2 $\AA$ are moderate, and 3.2-4.0 $\AA$ are weak (Jeffrey 1997, Khayrani et al. 2021). In terms of the interaction between the protein and its ligand, hydrophobic interactions are the most dominant (Khayrani et al. 2021). Referencing to literature, several standard values of distance cutoffs to consider 
the formation of hydrophobic interactions have been found and the optimum range is in between 3.3 - $3.8 \AA$ (Janiak 2000). While other researchers have suggested a relatively higher ranges (Burley and Petsko 1985, Peikert et al. 2014, Piovesan et al. 2016). The interactions and active site residues responsible for bindings between surfactants and target protein Cytochrome c oxidase subunit 2 of Cyprinus carpio and Cytochrome c oxidase subunit 1 of Tubifex tubifex are presented in Fig 8 and 9 respectively.

Table 2: Vina score between modelled protein and surfactants

\begin{tabular}{|c|c|c|}
\hline $\begin{array}{c}\text { Modelled protein } \\
\text { carpio) }\end{array}$ & Ligand & $\begin{array}{c}\text { Vina score/ docking score } \\
\text { (kcal/mol units) }\end{array}$ \\
\hline $\begin{array}{c}\text { Cytochrome c oxidase subunit 2 (Cyprinus } \\
\text { carpio) }\end{array}$ & SDS & -5.6 \\
\hline $\begin{array}{c}\text { Cytochrome c oxidase subunit 2 (Cyprinus } \\
\text { carpio) }\end{array}$ & CPC & -6 \\
\hline $\begin{array}{c}\text { Cytochrome c oxidase subunit 2 (Cyprinus } \\
\text { tubifex) }\end{array}$ & SLES & -4.9 \\
\hline $\begin{array}{c}\text { Cytochrome c oxidase subunit 1 (Tubifex } \\
\text { tubifex) }\end{array}$ & SDS & -6 \\
\hline $\begin{array}{c}\text { Cytochrome c oxidase subunit 1 (Tubifex } \\
\text { tubifex) }\end{array}$ & CPC & -7 \\
\hline Cytochrome c oxidase subunit 1 (Tubifex & SLES & -6 \\
\hline
\end{tabular}


bioRxiv preprint doi: https://doi.org/101101/2021.07.09.451643: this version posted July 10,2021 . The copyright holder for this preprin made available under aCC-BY-ND 4.0 International license.

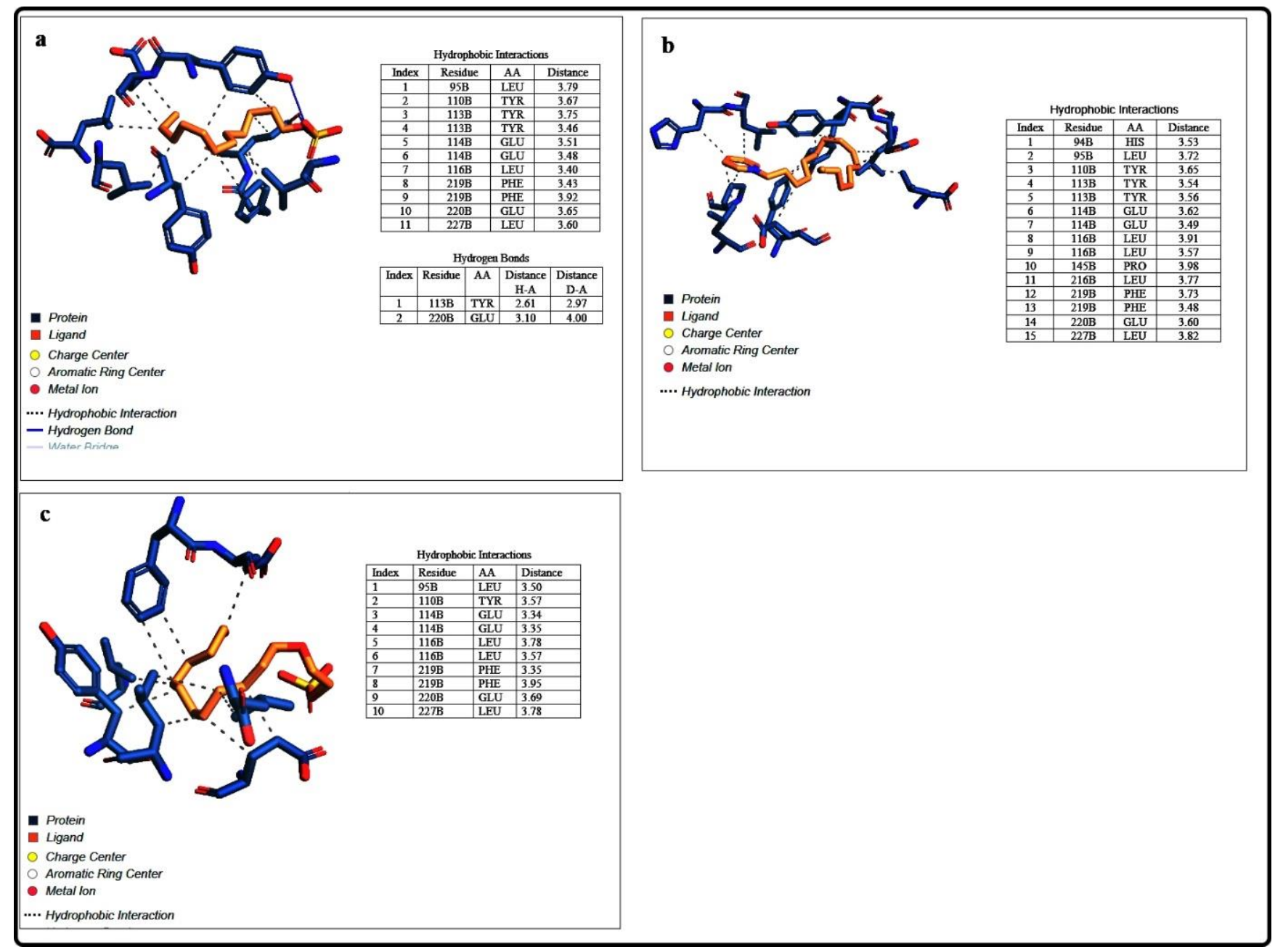

Fig 8: Types of interaction between (a): Cytochrome c oxidase subunit 2 of Cyprinus carpio and SDS, (b): Cytochrome c oxidase subunit 2 of Cyprinus carpio and CPC, (c): Cytochrome c oxidase subunit 2 of Cyprinus carpio and SLES. 


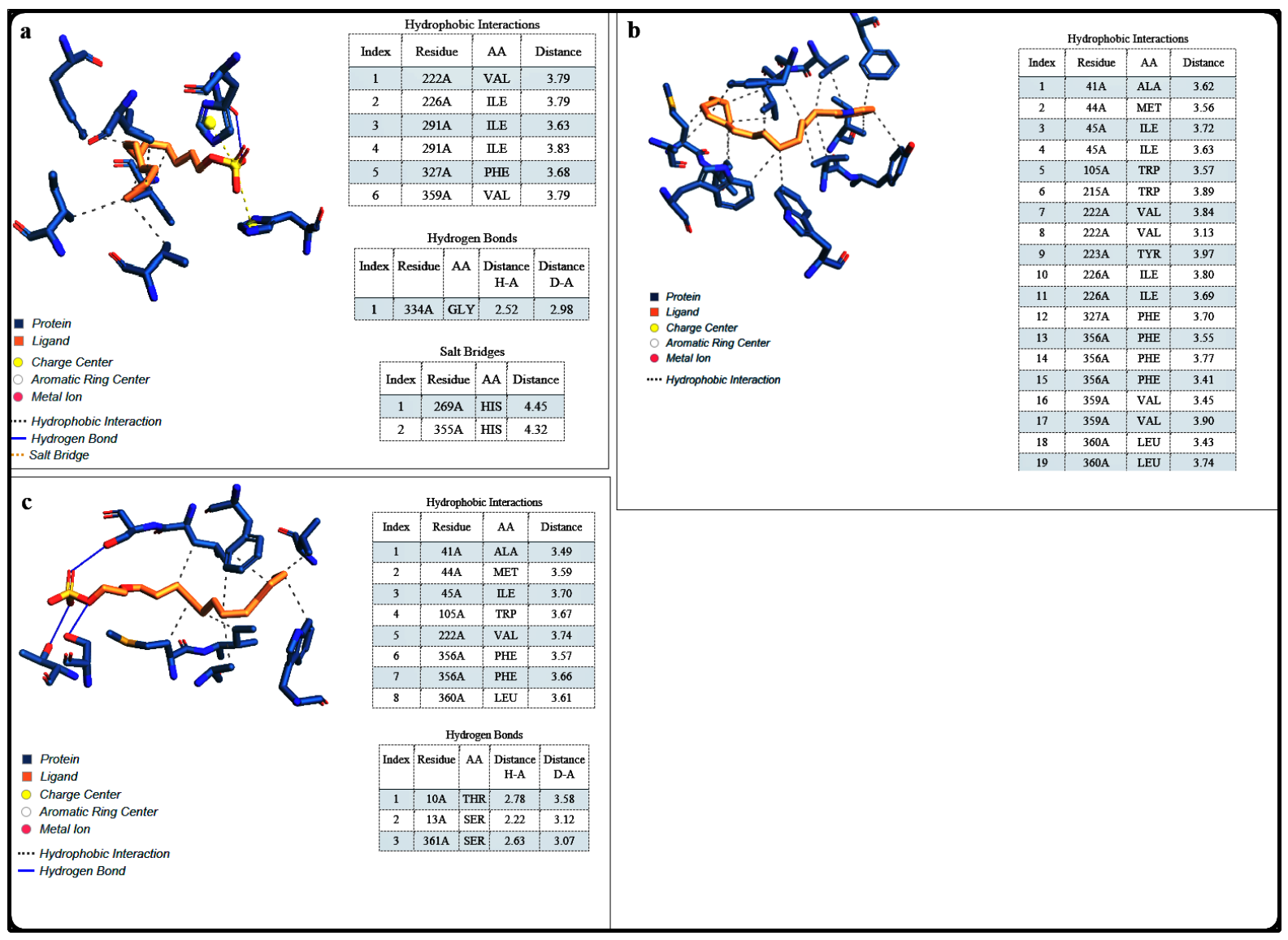

Fig 9: Types of interaction between (a): Cytochrome c oxidase subunit 1 of Tubifex tubifex and SDS, (b): Cytochrome c oxidase subunit 1 of Tubifex tubifex and CPC, (d): Cytochrome c oxidase subunit 1 of Tubifex tubifex and SLES.

In the case of Cytochrome c oxidase subunit 2 of Cyprinus carpio SDS demonstrated the vina score of $-6 \mathrm{kcal} / \mathrm{mol}$ associated with hydrophobic interaction with the residues of Leu 95, Tyr 110, Tyr 113, Glu 114, Leu 116, Phe 219, Glu 220, Leu 227, and hydrogen bonding with residues Tyr 113 and Glu 220 as well as salt bridge interaction with residues His 269 and 355. CPC demonstrated the vina score of $-7 \mathrm{kcal} / \mathrm{mol}$ with hydrophobic interaction with the residues of His 94, Leu 95, Tyr 110, Tyr 113, Glu 114, Leu 116, Pro 145, Leu 216, Phe 219, Glu 220, Leu 227. SLES demonstrated the vina score of $-6 \mathrm{kcal} / \mathrm{mol}$ with hydrophobic interaction with the residues of Leu 95, 116, 227, Tyr 110, Glu 114, Phe 219 and Glu 220.

Moreover in case of Cytochrome c oxidase subunit 1 of Tubifex tubifex SDS demonstrated the vina score of $-6 \mathrm{kcal} / \mathrm{mol}$ associated with hydrophobic interaction with the residues of Val 222, 359 Ile 226, 291 and Phe 327 and hydrogen bonding with residues Gly 334. CPC demonstrated the vina score of $-7 \mathrm{kcal} / \mathrm{mol}$ with hydrophobic interaction with the residues of Ala 41, Met 44, Ile 45, 226, Trp 105, 215, Val 222, 359, Tyr 223, Phe 327, 356 and Leu 360. 
Moreover, SLES demonstrated the vina score of $-6 \mathrm{kcal} / \mathrm{mol}$ with hydrophobic interaction with the residues of Ala 41, Met 44, Ile 45, Trp 105, Val 222, Phe 356, Leu 360, and hydrogen bonding with residues Thr 10, Ser 13 and 361. However, based on the vina score, it is fairly obvious that the surfactant CPC interacted the best with Cytochrome c oxidase subunit 2 of Cyprinus carpio and Cytochrome c oxidase subunit 1 of Tubifex tubifex. SDS and SLES also interact with the modelled proteins, albeit to a lower extent than CPC. Thus these results are in good concordance with the outcome of several researchers who reported that cationic surfactants are more toxic than anionic surfactants in aquatic organisms (Jardak et al. 2016). This might be due to this increased binding affinity of cationic surfactants to Cytochrome c oxidase than anionic surfactants. In our study in terms of the interaction between the protein and surfactants, maximum number and occurrence of hydrophobic interactions with the active site residues were observed rather than hydrogen bonds and salt bridges and the maximum existence of this hydrophobic interactions within the catalytic sites may indicate that the surfactants can proceed with inhibitory activity (Khayrani et al. 2021).

\section{Molecular dynamics (MD) studies}

To explore the structural and dynamic changes, we identified the residues regions of Cytochrome c oxidase (Tubifex tubifex) and Cytochrome c oxidase (Cyprinus carpio) either in unbounded or bounded with ligands form by analyzing the structural mobility based on the RMSF of the backbone atoms with respect to the initial structure. The conformational consistency of the docked poses is expressed by the RMSF values. The higher RMSF most likely are loop regions with more conformational flexibility, whereas the lower value reflects the proteins' restricted movement (Shah et al. 2021). As per our findings, the maximum RMSF value for both enzymes: Cytochrome c oxidase (Cyprinus carpio) and Cytochrome c oxidase (Tubifex tubifex) in unbounded cases are: $7.8 \AA$ and $6.1 \AA$ respectively [Figure 10(a,e)]. On the other hand, we can observe that the RMSF values obtained in the bounded structure are low compared to the unbounded form [Figure $10(\mathbf{b}, \mathbf{c}, \mathbf{d}, \mathbf{f}, \mathbf{g , ~ h})]$.

Cytochrome c oxidase (Cyprinus carpio) in unbounded form exhibited several fluctuations with the presence of high amplitudes at residues: 51 (RMSF $\approx 6 \AA$ ) and 129 (RMSF $\approx 7.8 \AA$ ). In addition, the RMSF values of Cytochrome c oxidase (Cyprinus carpio) in SDS bounded form indicated a slight fluctuation in regions of the residues: 5 (RMSF $\approx 3.4 \AA$ ), 56 (RMSF $\approx 3.5 \AA$ ) and $200(\mathrm{RMSF} \approx 3.2 \AA)$ [Fig10(f)].Also, the RMSF values of Cytochrome c oxidase (Cyprinus carpio) in SLES bounded are low in the residues: 51 (RMSF $\approx 4.6 \AA$ ) and 130 
(RMSF $\approx 3.6 \AA$ ) but exception in residue: 202 (RMSF $\approx 5.2 \AA$ ) which showed steep RMSF fluctuations in this residue [Fig10(g)]. Finally, the RMSF values of Cytochrome c oxidase (Cyprinus carpio) in CPC bounded form are low in the following residues: 52 (RMSF $\approx 4.1$ $\AA), 57(\mathrm{RMSF} \approx 3.9 \AA), 132(\mathrm{RMSF} \approx 3.3 \AA)$ and $200(\mathrm{RMSF} \approx 3.7 \AA)$ [Fig10(h)].

In the case of Tubifex tubifex, several fluctuations are present with the persistence of high amplitudes in different residues of Cytochrome c oxidase [25 (RMSF $\approx 6.1 \AA$ and 111 (RMSF $\approx 3.8 \AA$ ] in unbounded form [Fig 10(a)]. Residue wise comparison exhibited that the RMSF values of the same residues 25 and 111 is much lower in SDS bounded [25 $(\mathrm{RMSF} \approx 3.3 \AA, 111(\mathrm{RMSF} \approx 2.3 \AA)]$, SLES bounded [(25 (RMSF $\approx 3.4 \AA, 111(\mathrm{RMSF} \approx 2.3 \AA$ )] and CPC bounded [25 (RMSF $\approx 3.7 \AA, 111(\mathrm{RMSF} \approx 2.6 \AA)]$ form [Fig. 10 (b, c and d)].

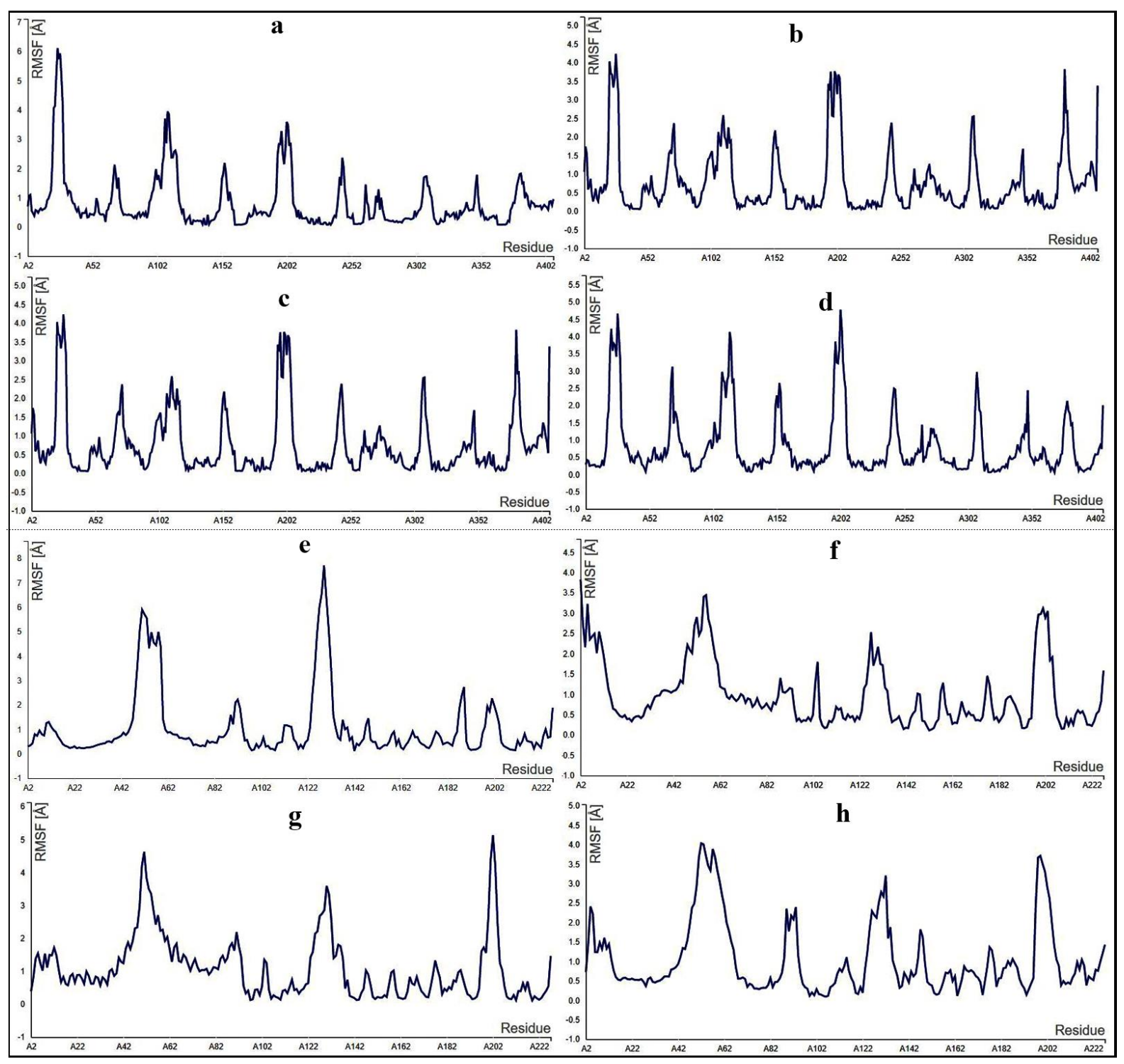

Fig 10: Molecular dynamics simulation showing the RMSF of (a) an unbounded Cytochrome c oxidase (Tubifex tubifex) (b) Cytochrome c oxidase (Tubifex tubifex) bound to SDS (c) 
Cytochrome c oxidase (Tubifex tubifex) bound to SLES (d) Cytochrome c oxidase (Tubifex tubifex) bound to CPC (e) unbounded Cytochrome c oxidase of Cyprinus carpio (f) Cytochrome c oxidase (Cyprinus carpio) bound to SDS (g) Cytochrome c oxidase (Cyprinus carpio) bound to SLES (h) Cytochrome c oxidase (Cyprinus carpio) bound to CPC.

Thus our results indicate that the binding of the residues of protein to the ligands affects the local structure and conformation of the protein.

\section{Conclusion}

The result suggests that the commonly used surfactants Sodium dodecyl sulphate, Cetylpyridinium chloride and Sodiun laureth sulphate might impart detrimental effect on the structure and dynamics of Cytochrome c oxidase in fish and fish food organism by binding with it in varying degrees. Due to this preliminary encouraging result based on Insilico assessment, further studies are required in the field trials for validation of our findings.

\section{Ethical approval}

This study does not include animal experiments by the authors that require the ethics committee's permission.

\section{Funding}

The research did not receive any specific grant from funding agencies in the public, commercial or nonprofit sectors.

\section{Conflict of interest}

The authors declare that they have no conflict of interest.

\section{Acknowledgment}

The authors are thankful to the Department of Zoology, The University of Burdwan for giving all sorts of technical and computational facilities to conduct this research. 


\section{References}

Adasme, M.F., Linnemann, K.L., Bolz, S.N., Kaiser, F., Salentin, S., Haupt, V.J., and Schroeder, M., 2021. PLIP 2021: expanding the scope of the protein-ligand interaction profiler to DNA and RNA. Nucleic Acids Research.

Arora, S., Lohiya, G., Moharir, K., Shah, S., and Yende, S., 2020. Identification of Potential Flavonoid Inhibitors of the SARS-CoV-2 Main Protease 6YNQ: A Molecular Docking Study. Digital Chinese Medicine, 3 (4).

Barra Caracciolo, A., Cardoni, M., Pescatore, T., and Patrolecco, L., 2017. Characteristics and environmental fate of the anionic surfactant sodium lauryl ether sulphate (SLES) used as the main component in foaming agents for mechanized tunnelling. Environmental Pollution.

Bhattacharya, D. and Cheng, J., 2013. 3Drefine: Consistent protein structure refinement by optimizing hydrogen bonding network and atomic-level energy minimization. Proteins: Structure, Function and Bioinformatics, 81 (1).

Bhattacharya, R., Chatterjee, A., Chatterjee, S., and Saha, N.C., 2021. Acute toxicity and sublethal effects of sodium laureth sulfate on oxidative stress enzymes in benthic oligochaete worm, Tubifex tubifex. Comparative Biochemistry and Physiology Part - C: Toxicology and Pharmacology, 243.

Bhattacharya, R., Chatterjee, A., and Saha, N.C., 2019a. Acute toxicity and ethological responses of oligochaete worm Tubifex tubifex (Muller) exposed to a cationic surfactant Cetylpyridinium chloride. International Journal of Scientific Research in Biological Sciences, 6 (2), 8-14.

Bhattacharya, R., Chatterjee, A., and Saha, N.C., 2019b. Sodium Dodecyl Sulphate induced acute toxicity and ethological responses to oligochaete worm Tubifex tubifex ( Muller ). Research Review International Journal of Multidisciplinary, 3085 (06), 160-164.

Bienert, S., Waterhouse, A., De Beer, T.A.P., Tauriello, G., Studer, G., Bordoli, L., and Schwede, T., 2017. The SWISS-MODEL Repository-new features and functionality. Nucleic Acids Research, 45 (D1).

Bondi, C.A.M., Marks, J.L., Wroblewski, L.B., Raatikainen, H.S., Lenox, S.R., and Gebhardt, K.E., 2015. Human and Environmental Toxicity of Sodium Lauryl Sulfate 
(SLS): Evidence for Safe Use in Household Cleaning Products. Environmental Health Insights.

Breda, A., Valadares, N.F., Souza, O.N. de, and Garratt, R.C., 2007. Protein Structure, Modelling and Applications. Bioinformatics in Tropical Disease Research: A Practical and Case-Study Approach, (Md).

Burley, A.S.K. and Petsko, G. a, 1985. Aromatic-Aromatic Interaction: A Mechanism of Protein Structure Stabilization Author(s): S. K. Burley and G. A. Petsko Source: Science, 229 (4708), 23-28.

Chang, K.Y. and Yang, J.R., 2013. Analysis and Prediction of Highly Effective Antiviral Peptides Based on Random Forests. PLoS ONE, 8 (8).

Chaturvedi, V. and Kumar, A., 2010. Toxicity of Sodium Dodecyl Sulfate in Fishes and Animals. Int J Appl Biol Pharmaceut Tech, I (2), 630-633.

Colovos, C. and Yeates, T.O., 1993. Verification of protein structures: Patterns of nonbonded atomic interactions. Protein Science, 2 (9).

Costa, X., Laguna, E., Herrera, D., Serrano, J., Alonso, B., and Sanz, M., 2013. Efficacy of a new mouth rinse formulation based on $0.07 \%$ cetylpyridinium chloride in the control of plaque and gingivitis: A 6-month randomized clinical trial. Journal of Clinical Periodontology, 40 (11), 1007-1015.

Dhandare, B.C., Rather, M.A., Bhosale, B.P., Pawar, R., Guttula, P.K., and Pagarkar, A.U., 2020. Molecular modeling, docking and dynamic simulations of growth hormone receptor (GHR) of Labeo rohita. Journal of Biomolecular Structure and Dynamics.

Ebele, A.J., Abou-Elwafa Abdallah, M., and Harrad, S., 2017. Pharmaceuticals and personal care products (PPCPs) in the freshwater aquatic environment. Emerging Contaminants.

Freitas, R., Silvestro, S., Coppola, F., Costa, S., Meucci, V., Battaglia, F., Intorre, L., Soares, A.M.V.M., Pretti, C., and Faggio, C., 2020. Toxic impacts induced by Sodium lauryl sulfate in Mytilus galloprovincialis. Comparative Biochemistry and Physiology-Part A : Molecular and Integrative Physiology, 242.

Freitas, R., Silvestro, S., Coppola, F., Meucci, V., Battaglia, F., Intorre, L., Soares, A.M.V.M., Pretti, C., and Faggio, C., 2019. Biochemical and physiological responses induced in Mytilus galloprovincialis after a chronic exposure to salicylic acid. Aquatic 
Toxicology, 214.

Freitas, R., Silvestro, S., Pagano, M., Coppola, F., Meucci, V., Battaglia, F., Intorre, L., Soares, A.M.V.M., Pretti, C., and Faggio, C., 2020. Impacts of salicylic acid in Mytilus galloprovincialis exposed to warming conditions. Environmental Toxicology and Pharmacology, 80.

Gasteiger, E., Bairoch, A., Sanchez, J.C., Williams, K.L., Appel, R.D., Hochstrasser, D.F., and Wilkins, M.R., 1999. Protein identification and analysis tools in the ExPASy server. Methods in molecular biology (Clifton, N.J.), 112.

Hering, I., Eilebrecht, E., Parnham, M.J., Günday-Türeli, N., Türeli, A.E., Weiler, M., Schäfers, C., Fenske, M., and Wacker, M.G., 2020. Evaluation of potential environmental toxicity of polymeric nanomaterials and surfactants. Environmental Toxicology and Pharmacology, 76.

Ivanković, T. and Hrenović, J., 2010. Surfactants in the environment. Arhiv za Higijenu Rada i Toksikologiju.

Jackson, M., Eadsforth, C., Schowanek, D., Delfosse, T., Riddle, A., and Budgen, N., 2016. Comprehensive review of several surfactants in marine environments: Fate and ecotoxicity. Environmental Toxicology and Chemistry.

Janiak, C., 2000. A critical account on n-n stacking in metal complexes with aromatic nitrogen-containing ligands. Journal of the Chemical Society, Dalton Transactions, (21), 3885-3896.

Jardak, K., Drogui, P., and Daghrir, R., 2016. Surfactants in aquatic and terrestrial environment: occurrence, behavior, and treatment processes. Environmental Science and Pollution Research, 23 (4), 3195-3216.

Jeffrey, G.A., 1997. An introduction to hydrogen bonding. Oxford University Press.

Kaur, A., Pati, P.K., Pati, A.M., and Nagpal, A.K., 2020. Physico-chemical characterization and topological analysis of pathogenesis-related proteins from Arabidopsis thaliana and Oryza sativa using in-silico approaches. PLoS ONE, 15 (9 September).

Khayrani, A.C., Irdiani, R., Aditama, R., Pratami, D.K., Lischer, K., Ansari, M.J., Chinnathambi, A., Alharbi, S.A., Almoallim, H.S., and Sahlan, M., 2021. Evaluating the potency of Sulawesi propolis compounds as ACE-2 inhibitors through molecular 
docking for COVID-19 drug discovery preliminary study. Journal of King Saud University - Science, 33 (2).

Khusro, A., Aarti, C., Mahizhaveni, B., Dusthackeer, A., Agastian, P., Esmail, G.A., Ghilan, A.K.M., Al-Dhabi, N.A., and Arasu, M.V., 2020. Purification and characterization of anti-tubercular and anticancer protein from Staphylococcus hominis strain MANF2: In silico structural and functional insight of peptide. Saudi Journal of Biological Sciences, 27 (4).

Klebe, G., 2006. Virtual ligand screening: strategies, perspectives and limitations. Drug Discovery Today.

Kurcinski, M., Oleniecki, T., Ciemny, M.P., Kuriata, A., Kolinski, A., and Kmiecik, S., 2019. CABS-flex standalone: A simulation environment for fast modeling of protein flexibility. Bioinformatics, 35 (4).

Laskowski, R.A., MacArthur, M.W., Moss, D.S., and Thornton, J.M., 1993. PROCHECK: a program to check the stereochemical quality of protein structures. Journal of Applied Crystallography, 26 (2).

Leavesley, H.B., Li, L., Prabhakaran, K., Borowitz, J.L., and Isom, G.E., 2008. Interaction of cyanide and nitric oxide with Cytochrome c oxidase: Implications for acute cyanide toxicity. Toxicological Sciences, 101 (1).

Lechuga, M., Fernández-Serrano, M., Jurado, E., Núñez-Olea, J., and Ríos, F., 2016. Acute toxicity of anionic and non-ionic surfactants to aquatic organisms. Ecotoxicology and Environmental Safety, 125, 1-8.

Liu, J. and Wang, R., 2015. Classification of current scoring functions. Journal of Chemical Information and Modeling, 55 (3).

Liu, Y., Grimm, M., Dai, W. tao, Hou, M. chun, Xiao, Z.X., and Cao, Y., 2020. CB-Dock: a web server for cavity detection-guided protein-ligand blind docking. Acta Pharmacologica Sinica, 41 (1).

Marechal, Y., 2007. The Hydrogen Bond and the Water Molecule: The Physics and Chemistry of Water, Aqueous and Bio Media. The Hydrogen Bond and the Water Molecule: The Physics and Chemistry of Water, Aqueous and Bio Media.

Mustapha, D.S. and Bawa-Allah, K.A., 2020. Differential toxicities of anionic and nonionic 
surfactants in fish. Environmental Science and Pollution Research, 27 (14), 1675416762.

Peikert, M., Chen, X., Chi, L., Brezesinski, G., Janich, S., Würthwein, E.U., and Schäfer, H.J., 2014. Phase behavior and molecular packing of octadecyl phenols and their methyl ethers at the air/water interface. Langmuir, 30 (20), 5780-5789.

Piovesan, D., Minervini, G., and Tosatto, S.C.E., 2016. The RING 2.0 web server for high quality residue interaction networks. Nucleic acids research, 44 (W1), W367-W374.

Puchta, R., 1984. Cationic surfactants in laundry detergents and laundry aftertreatment aids. Journal of the American Oil Chemists'Society, 61 (2), 367-376.

Ramírez, D. and Caballero, J., 2018. Is It Reliable to Take the Molecular Docking Top Scoring Position as the Best Solution without Considering Available Structural Data? Molecules, 23 (5).

Saier, M.H., Reddy, V.S., Tsu, B. V., Ahmed, M.S., Li, C., and Moreno-Hagelsieb, G., 2016. The Transporter Classification Database (TCDB): Recent advances. Nucleic Acids Research, 44 (D1).

Salentin, S., Schreiber, S., Haupt, V.J., Adasme, M.F., and Schroeder, M., 2015. PLIP: Fully automated protein-ligand interaction profiler. Nucleic Acids Research, 43 (W1).

Schiffer, M. and Edmundson, A.B., 1967. Use of Helical Wheels to Represent the Structures of Proteins and to Identify Segments with Helical Potential. Biophysical Journal, 7 (2).

Shah, S., Chaple, D., Arora, S., Yende, S., Moharir, K., and Lohiya, G., 2021. Exploring the active constituents of Oroxylum indicum in intervention of novel coronavirus (COVID19) based on molecular docking method. Network Modeling Analysis in Health Informatics and Bioinformatics, 10 (1).

Shaw, K.L., Grimsley, G.R., Yakovlev, G.I., Makarov, A.A., and Pace, C.N., 2001. The effect of net charge on the solubility, activity, and stability of ribonuclease Sa. Protein Science, 10 (6).

Srinivasan, S. and Avadhani, N.G., 2012. Cytochrome c oxidase dysfunction in oxidative stress. Free Radical Biology and Medicine.

Vardhan, S. and Sahoo, S.K., 2020. In silico ADMET and molecular docking study on 
searching potential inhibitors from limonoids and triterpenoids for COVID-19. Computers in Biology and Medicine, 124.

Waterhouse, A., Bertoni, M., Bienert, S., Studer, G., Tauriello, G., Gumienny, R., Heer, F.T., De Beer, T.A.P., Rempfer, C., Bordoli, L., Lepore, R., and Schwede, T., 2018. SWISSMODEL: Homology modelling of protein structures and complexes. Nucleic Acids Research, 46 (W1).

Wikström, M., Krab, K., and Sharma, V., 2018. Oxygen Activation and Energy Conservation by Cytochrome c oxidase. Chemical Reviews.

Wójcikowski, M., Ballester, P.J., and Siedlecki, P., 2017. Performance of machine-learning scoring functions in structure-based virtual screening. Scientific Reports, 7.

Zhang, C., Cui, F., Zeng, G. ming, Jiang, M., Yang, Z. zhu, Yu, Z. gang, Zhu, M. ying, and Shen, L. qing, 2015. Quaternary ammonium compounds (QACs): A review on occurrence, fate and toxicity in the environment. Science of the Total Environment. 